\title{
Commentary on the WHO 2008 classification of immunodeficiency-associated lymphoproliferative disorders
}

\author{
Elena Ivan • Megan S. Lim
}

Received: 7 January 2011 / Accepted: 2 February 2011 / Published online: 19 February 2011

(C) Springer-Verlag 2011

\begin{abstract}
The 2008 WHO update of Classification of Tumours of Hematopoietic and Lymphoid Tissues revised the classification of immunodeficiency-associated lymphoproliferative disorders with the aim to better define these heterogeneous entities to better distinguish between reactive and neoplastic lesions, further refine some entities (plasmablastic lymphoma, monomorphic post-transplant lymphoproliferative disorders and other iatrogenic immunodeficiencyassociated lymphoproliferative disorders), and introduce a new lymphoma entity (large B-cell lymphoma arising in HHV8-associated multicentric Castleman disease). The purpose of this review is to highlight the changes in the 2008 WHO classification of immunodeficiency-associated lymphoproliferative disorders.
\end{abstract}

Keywords Immunodeficiency - Lymphoproliferative disorder $\cdot$ Immune disorder $\cdot$ Lymphoma

\section{Introduction}

Immunodeficiency-associated lymphoproliferative disorders occur in the setting of primary immunodeficiency syndromes, human immunodeficiency virus (HIV) infections, post-transplant-related and other iatrogenic immunosuppressions. They comprise a spectrum of lymphoid

\section{E. Ivan}

The University of Michigan,

Ann Arbor, MI, USA

\section{S. Lim $(\bowtie)$}

Department of Pathology, The University of Michigan,

1301 Catherine Street, 5242 Medical Science I - SPC 5602,

Ann Arbor, MI 48109, USA

e-mail:meganlim@umich.edu proliferations that range from reactive hyperplasias to lymphomas. The lymphomas associated with these disorders include those usually described in immunocompetent patients and lymphomas that are more frequently associated with immunocompromised individuals.

In an effort to better characterize these heterogeneous lymphoproliferative disorders (LPD), the 2008 WHO made a series of changes refining some of the previously described entities and introducing a new one. LPD associated with primary immune disorders are now separated into nonneoplastic and neoplastic categories. In the lymphomas associated with HIV category, the definition of plasmablastic lymphoma of the oral cavity was changed to plasmablastic lymphoma and a new entity (large B-cell lymphoma arising in HHV8-associated multicentric Castleman disease) was introduced. The monomorphic post-transplant lymphoproliferative disorders (PTLD) are now redefined to exclude indolent B-cell lymphoma. The old category of "methotrexate-associated LPD" is replaced by "other iatrogenic immunodeficiency-associated LPD" [1, 2$]$.

Lymphoproliferative diseases associated with primary immune disorders

Primary immunodeficiencies (PID) are a heterogeneous group of congenital disorders caused by defects in different elements of the adaptive or innate immune system. The advances in molecular genetics and immunology during the last years have made possible the identification of more genes causing PID, a better understanding of the pathophysiology of these disorders thereby facilitating better clinical detection and confirmation of PID [3]. The heterogeneity of LPD arising in PID is due to the effect of different mutations within the PID-causing genes and of epigenetic and environmental factors. In the new WHO 
classification, the LPD associated with PID are separated into non-neoplastic lesions (including reactive hyperplasias due to the underlying immunodeficiency or associated Epstein-Barr virus (EBV) infection and polymorphous proliferations similar to those seen in post-transplant patients) and lymphomas. The lymphomas occurring in patients with PID do not differ from those occurring in immunocompetent hosts, with the most commonly seen lymphomas being diffuse large B-cell lymphomas (DLBCL), but with other lymphomas also occurring (Burkitt lymphoma, Hodgkin lymphoma, peripheral T-cell lymphoma, etc.). In the 2008 WHO classification, no significant changes have been made for the lymphomas associated with PID.

\section{Lymphomas associated with HIV infection}

HIV infections are associated with lymphomas that can occur earlier or later in the course of the disease and are predominantly aggressive B-cell lymphomas. With the extensive use of highly active antiretroviral therapy (HAART) in the treatment of HIV infections, several epidemiological changes have been seen, including a decreased incidence of non-Hodgkin lymphomas and an increased incidence of Hodgkin lymphoma, trends that parallel the improvement in CD4 counts. An increase in nodal involvement and a decrease in the incidence of EBV-positive lymphomas have also been noted in the HAART era.

The lymphomas associated with HIV infection are divided in three categories: lymphomas that also occur in the immunocompetent patients, lymphomas occurring more specifically in HIV-positive patients and lymphomas occurring in other immunodeficiency states (polymorphic lymphoid proliferations resembling PTLD).

In the first category, the most frequently seen are Burkitt lymphoma (BL), diffuse large B-cell lymphoma and Hodgkin lymphoma, while MALT lymphoma, peripheral T-cell and NK-cell lymphomas are rarely seen. Of note, in the 2008 WHO classification the BL with plasmacytoid differentiation and the atypical $\mathrm{BL}$ are no longer formally designated and are considered part of the morphological spectrum of BL since they share the same gene expression profile. With more than a decade of effective antiretroviral therapy, full-dose lymphoma therapies have become standard and the survival of HIV-positive patients with DLBCL has improved and approaches that of de novo DLBCL occurring in immunocompetent patients. The main prognostic factor is the achievement of complete remission.

The most important changes in the 2008 WHO classification are in the category of lymphomas occurring more specifically in HIV-positive patients, introducing a new entity, large B-cell lymphoma arising in the HHV8-associated multicentric Castleman disease (HHV8-MCD) and refining the definition of the plasmablastic lymphoma.

Large B-cell lymphoma arising in HHV8-MCD is a monoclonal proliferation of HHV8-infected lymphoid cells resembling plasmablasts that develops in multicentric Castleman disease. It predominantly involves the lymph nodes and the spleen. The cells composing this lymphoma are naive IgM producing plasma cells without IG somatic hypermutation that are positive for HHV8 latent nuclear antigen 1(LANA-1), viral interleukin-6, and show immunoglobulin $\lambda$ light chain restriction. They are EBV-negative as opposed to the plasmablastic lymphoma that has similar plasmablastic morphology but is EBV-positive and HHV8-negative.

In the new WHO, the plasmablastic lymphoma is not considered a subtype of DLBCL but a separate entity and has a broadened definition to include cases outside the oral cavity and cases associated with immunodeficiency states other than HIV infections. The 2008 WHO classification emphasizes its distinction from the anaplastic plasma cell myeloma. The high proliferation index, extranodal localization, history of immunodeficiency and EBV positivity characteristic for plasmablastic lymphoma are useful in making this distinction.

No significant changes have been made in the 2008 WHO for primary effusion lymphoma (PEL). New gene expression profiling studies demonstrated that AIDS-associated PEL has a distinct profile with features of both plasma cells and EBV-transformed lymphoblastoid cell lines [4].

\section{Post-transplant lymphoproliferative disorders (PTLDs)}

PTLDs are lymphoid/plasmacytic proliferations that develop after solid organ, bone marrow, stem cell, or umbilical cord transplants as a consequence of the accompanying immunosuppression. PTLD are classified into early lesions, polymorphic PTLD, monomorphic PTLD, and Hodgkin lymphoma-type PTLD mainly based on morphology.

While acknowledging that PTLD comprise a spectrum of lymphoid proliferations ranging from early lesions to lymphomas, which are sometimes difficult to separate from each other or distinguish from other entities, 2008 WHO tries to better define these subtypes. The early lesions include plasma cell hyperplasia and infectious mononucleosis-like lesions. The new WHO classification recommends the distinction of early lesions from other reactive lymphoid proliferations based on the extent of the proliferation, clinical correlation, and assessment of the EBER-1 in situ hybridization.

Polymorphic PTLD comprise a spectrum of morphologically polymorphic lymphoid proliferations that destroy the architecture of the involved lymph nodes or extranodal 
Table 1 Summary of changes in the classification of immunodeficiency-associated lymphoproliferative disorders

\begin{tabular}{|c|c|c|}
\hline WHO 2001 classification & WHO 2008 classification & Comments \\
\hline $\begin{array}{l}\text { Lymphoproliferative diseases associated } \\
\text { with primary immune disorders }\end{array}$ & $\begin{array}{l}\text { Lymphoproliferative diseases associated } \\
\text { with primary immune disorders }\end{array}$ & $\begin{array}{l}\text { Separation of non-neoplastic proliferations } \\
\text { from lymphomas }\end{array}$ \\
\hline Precursor lesions & Non-neoplastic lesions & \\
\hline B-cell neoplasms & Lymphomas & \\
\hline \multicolumn{3}{|l|}{ T-cell neoplasms } \\
\hline \multicolumn{3}{|l|}{ Hodgkin lymphoma } \\
\hline $\begin{array}{l}\text { Lymphomas associated with infection by } \\
\text { the human immune deficiency virus } \\
\text { (HIV) }\end{array}$ & $\begin{array}{l}\text { Lymphomas associated with HIV } \\
\text { infection }\end{array}$ & \\
\hline $\begin{array}{l}\text { Lymphomas also occurring in } \\
\text { immunocompetent patients }\end{array}$ & $\begin{array}{l}\text { Lymphomas also occurring in } \\
\text { immunocompetent patients }\end{array}$ & \\
\hline Burkitt lymphoma & Burkitt lymphoma & $\begin{array}{l}\text { Morphological variants for BL are no longer } \\
\text { formally designated }\end{array}$ \\
\hline \multicolumn{3}{|l|}{ Classical BL } \\
\hline \multicolumn{3}{|l|}{ BL with plasmacytoid differentiation } \\
\hline \multicolumn{3}{|l|}{ Atypical BL } \\
\hline Diffuse large B-cell lymphoma & Diffuse large B-cell lymphoma & No changes for the other types of lymphomas \\
\hline Classical Hodgkin lymphoma & Hodgkin lymphoma & \\
\hline Other lymphomas & Other lymphomas & \\
\hline $\begin{array}{l}\text { Lymphomas occurring more specifically } \\
\text { in HIV-positive patients }\end{array}$ & $\begin{array}{l}\text { Lymphomas occurring more specifically } \\
\text { in HIV-positive patients }\end{array}$ & \\
\hline Primary effusion lymphoma & Pleural effusion lymphoma & No changes \\
\hline \multirow[t]{2}{*}{$\begin{array}{l}\text { Plasmablastic lymphoma of the oral } \\
\text { cavity }\end{array}$} & Plasmablastic lymphoma & $\begin{array}{l}\text { New definition of PB includes cases outside the oral } \\
\text { cavity and cases associated with other } \\
\text { immunodeficiencies }\end{array}$ \\
\hline & $\begin{array}{l}\text { Large B-cell lymphoma arising in } \\
\text { HHV8-associated multicenter Castle- } \\
\text { man disease }\end{array}$ & $\begin{array}{l}\text { New entity of lymphoma arising in HHV8 MCD, } \\
\text { composed of plasmablasts that are cIgM+, } \\
\text { HHV8+ and EBV- }\end{array}$ \\
\hline $\begin{array}{l}\text { Lymphomas also occurring in other } \\
\text { immunodeficiency states }\end{array}$ & $\begin{array}{l}\text { Lymphomas also occurring in other } \\
\text { immunodeficiency states }\end{array}$ & No changes \\
\hline $\begin{array}{l}\text { Polymorphic lymphoid proliferations } \\
\text { resembling PTLD }\end{array}$ & $\begin{array}{l}\text { Polymorphic lymphoid proliferations } \\
\text { resembling PTLD }\end{array}$ & \\
\hline $\begin{array}{l}\text { Post-transplant lymphoproliferative } \\
\text { disorders (PTLD) }\end{array}$ & $\begin{array}{l}\text { Post-transplant lymphoproliferative } \\
\text { disorders }\end{array}$ & \\
\hline Early lesions & Early lesions & No changes \\
\hline Polymorphic PTLD & Polymorphic PTLD & $\begin{array}{l}\text { Recommendation to include clonality in the pathology } \\
\text { reports for P-PTLD cases that show obvious clonality }\end{array}$ \\
\hline \multirow[t]{2}{*}{ Monomorphic PTLD } & Monomorphic PTLD & Excludes indolent lymphomas \\
\hline & & $\begin{array}{l}\text { Recommendation to include PTLD first in the } \\
\text { pathology reports, followed by the lymphoma type }\end{array}$ \\
\hline $\begin{array}{l}\text { Hodgkin lymphoma and Hodgkin } \\
\text { lymphoma-like PTLD }\end{array}$ & $\begin{array}{l}\text { Classical Hodgkin lymphoma type } \\
\text { PTLD }\end{array}$ & $\begin{array}{l}\text { Hodgkin lymphoma-like PTLD are considered } \\
\text { either P-PTLD or M-PTLD }\end{array}$ \\
\hline $\begin{array}{l}\text { Methotrexate-associated } \\
\text { lymphoproliferative disorders }\end{array}$ & $\begin{array}{l}\text { Other iatrogenic immunodeficiency- } \\
\text { associated lymphoproliferative disorders }\end{array}$ & $\begin{array}{l}\text { New definition includes LPD associated with other } \\
\text { immunosuppressive drugs, like anti TNF } \alpha\end{array}$ \\
\hline
\end{tabular}

tissues, but do not fulfill the criteria for any distinct lymphoma category. The distinction between polymorphic and monomorphic PTLD is based on a subjective assessment of the extent of the large transformed cells. Polymorphic PTLD may be composed of either polyclonal or clonal populations. The new WHO emphasizes, including the light chain class restriction in the pathology report for the polymorphic PTLD cases that show obvious clonality, since some of them could represent monomorphic DLBCL-like PTLD with plasmacytic differentiation, DLBCL-like PTLD with significant polymorphism, or plasma cell neoplasm with increased transformed cells.

The monomorphic PTLD are B-cell and T/NK-cell lymphomas that also occur in immunocompetent patients. 
This category is refined in the WHO 2008 classification to exclude the indolent B-cell lymphomas (e.g., follicular lymphoma and MALT lymphoma). The new WHO classification makes recommendations for the pathology report to include first PTLD in the diagnostic line followed by the type of lymphoma using the classification of lymphomas occurring in immunocompetent patients.

WHO 2008 recommends distinguishing between classical Hodgkin and Hodgkin-like lesions using both morphological and immunophenotypical criteria and considering the Hodgkin-like lesions as polymorphic or monomorphic PTLD based on morphologic evaluation.

Other iatrogenic immunodeficiency-associated lymphoproliferative disorders

In the former WHO classification "methotrexate-associated lymphoproliferative disorders" were regarded as lymphoproliferations occurring in patients receiving methotrexate treatment for autoimmune diseases. The new WHO classification changed the name of this category to "other iatrogenic immunodeficiency-associated lymphoproliferative disorders" to reflect the observation that other immunosuppressive drugs are also associated with LPD. This category excludes auto/allo-transplantation-associated lymphomas and iatrogenically related lymphomas supervening on hematological malignancies. The group of immunosuppressive drugs associated with LPD has been expanded to include TNF $\alpha$ antagonists used for the treatment of autoimmune diseases or inflammatory bowel disease.

The other iatrogenic immunodeficiency-associated LPD comprise a spectrum of lesions ranging from polymorphic or lymphoplasmacytic proliferations similar to those seen in PTLD to B-cell lymphomas, Hodgkin lymphomas, and T/NK-cell lymphomas. A new observation is the association between hepatosplenic T-cell lymphoma and young patients (frequently males) with Crohn's disease treated with infliximab in combination with 6-mercaptopurine and azathioprine. Although EBV is positive in many of these iatrogenic LPD, this cannot completely explain the development of lymphoma in all the cases. It is probably due to a combination of factors, including immnunosuppression, patient's genetic background and chronic inflammation, and antigenic stimulation [5].

\section{Conclusions}

In the updated, fourth edition of WHO classification of immunodeficiency-associated lymphoproliferative disorders, several changes have been made, reflecting the accumulation of information that has emerged from studies of the LPD associated with primary and acquired immunodeficiencies in the past several years. Table 1 summarizes the changes in the classification of immunodeficiencyassociated lymphoproliferative disorders.

As many of the immunodeficiency-associated LPD cases will respond to the reduction or withdrawal of immunosuppression, it is important to recognize these entities and distinguish them from de novo lymphomas. Further studies are necessary to advance the understanding of the etiology of these immunodeficiency-associated LPD and to develop preventive strategies.

Conflict of interest The authors declare that they have no conflict of interest.

\section{References}

1. Jaffe ES, Harris NL, Stein H et al (2001) WHO Classification of tumours: pathology and genetics of tumours of haematopoietic and lymphoid tissues. IARC Press, Lyon

2. Swerdlow SH, Campo E, Harris NL et al (2008) WHO Classification of tumours of haematopoietic and lymphoid tissues. IARC Press, Lyon

3. Lim MS, Elenitoba-Johnson KS (2004) The molecular pathology of primary immunodeficiencies. J Mol Diagn 6:59-83

4. Klein U, Gloghini A, Gaidano G et al (2003) Gene expression profile analysis of AIDS-related primary effusion lymphoma (PEL) suggests a plasmablastic derivation and identifies PEL-specific transcripts. Blood 101:4115-4121

5. Anderson LA, Gadalla S, Morton LM et al (2009) Populationbased study of autoimmune conditions and the risk of specific lymphoid malignancies. Int J Canc 125:398-405 